\section{International Scientific Journal Theoretical \& Applied Science}

\author{
p-ISSN: 2308-4944 (print) e-ISSN: 2409-0085 (online) \\ Year: 2017 Issue: 09 Volume: 53
}

Published: $30.09 .2017 \quad \underline{\text { http://T-Science.org }}$
Sabuhi Tahir Huseynov doctoral student of the department "Customs and international trade" of the Azerbaijan State Economic University, Baku, Azerbaijan Republic E-mail: nauka-xxi@mail.ru

SECTION 19. Management. Marketing. Public administration.

\title{
THE MODERN ECONOMIC AND ORGANIZATIONAL ASPECTS OF EXTERNAL TRADE MANAGEMENT BY CONSUMER GOODS
}

\begin{abstract}
The problems of modern economic and organizational aspects of managing foreign trade in consumer goods are discusses in this article. The problems and issues of development of foreign economic relations and foreign trade activities of the country in terms of the growth of global influences are analyzed with this purpose. The importance of efficiency of foreign trade activities and the productivity of foreign economic relations are revealed. The methodology for determining the economic efficiency of foreign trade management, including export-import transactions is developed. The calculations of the efficiency indicators of import operations and the cost of foreign currency funds are prepared. The influence of the level of foreign trade prices, the change in the structure of trade on the magnitude of the efficiency of exports and imports are studied. A number of proposals on current problems of economic and organizational aspects of managing foreign trade in consumer goods are summarized and given.

Key words: Azerbaijan, foreign trade, modern problems of foreign trade activities, economic and organizational problems of management of foreign trade, external trade, consumer goods, efficiency of exportimport operations, the adequacy of the foreign trade management in consumer goods.

Language: Russian

Citation: Huseynov ST (2017) THE MODERN ECONOMIC AND ORGANIZATIONAL ASPECTS OF EXTERNAL TRADE MANAGEMENT BY CONSUMER GOODS. ISJ Theoretical \& Applied Science, 09 (53): 201-205.

Soi: http://s-o-i.org/1.1/TAS-09-53-30 Doi: crossef https://dx.doi.org/10.15863/TAS.2017.09.53.30

\section{СОВРЕМЕННЫЕ ЭКОНОМИКО-ОРГАНИЗАЦИОННЫЕ АСПЕКТЫ УПРАВЛЕНИЯ ВНЕШНЕЙ ТОРГОВЛЕЙ ПОТРЕБИТЕЛЬСКИМИ ТОВАРАМИ}

Аннотация: В данной статье рассматриваются проблемы современных экономико-организационных аспектов управления внешней торговлей потребительскими товарами. С этой целью были анализированы проблемы и вопросы развития внешнеэкономических связей и внешнеторговой деятельности странь в условиях роста глобальных влияний. Раскрыта важность эффективности внешнеторговой деятельности и продуктивность внешнеэкономических связей. Разработана методика определения экономической эффективности управления внешней торговлей, включая экспортно-импортные операции. Подготовлены расчеты показателей эффективности импортных операций и затраты на них валютных средств. Изучено влияние уровня внешнеторговых иеен, изменение структуры торговли на величину эффективности экспорта и импорта. Обобщен и дан ряд предложений по современным проблемам экономикоорганизационных аспектов управления внешней торговлей потребительскими товарами.

Ключевые слова: Азербайджан, внешняя торговля, современные проблемы внешней торговой деятельности, экономико-организационные проблемы управления внешней торговли, управление внешней торговлей потребительских товаров, эффективность экспортно-импортных операций, адекватность управления внешней торговлей потребительских товаров.
\end{abstract}

\section{Introduction}

Отметим что, в современных условиях актуальной проблемой является способность страны производить определенное количество конкурентоспособных товаров для внешнего рынка, которая во многом зависит от освоенных природных ресурсов, экономических и производственных возможностей, наличия 
соответствующей инфраструктуры $[1 ; 2]$. В частности, определяющей целью развития экспорта, является совершенствование его структуры путем расширения его ассортимента и улучшение качества товаров, совершенствования географической структуры и развития прогрессивных форм международного торгового сотрудничества $[3 ; 4 ; 5 ; 6 ; 7 ; 8]$. Достижение этих целей в трансформационных условиях невозможно без совершенствования системы управления внешней торговли потребительскими товарами, без активного участия государства, формирующего благоприятные экономические, организационные, правовые и другие условия для развития внешнеторговых связей, а также оказывающего различные виды поддержки этой сложной подсистемы мировой торговли. По мере расширения внешнеторговых связей возникает потребность в новых инструментах для оптимизации участия страны в международной специализации, ограждения национальной экономики от влияния негативных явлений в мировой торговле, содействия укреплению позиций азербайджанских производителей на мировом рынке [9].

\section{Materials and Methods}

После восстановления независимости в качестве суверенного государства Азербайджан нуждался в разработке и осуществлении совершенно новой внешнеэкономической концепции и внешнеторговой стратегии с учетом национальных экономических интересов Азербайджана. Характерной особенностью модели внешнеэкономической политики Азербайджанской Республики в современных условиях является ориентация на экспорт, ограничение импорта и достижение экспортноимпортной сбалансированности. Об этом свидетельствует стабильное положительное сальдо внешнеторгового баланса страны за последние годы. Однако данная положительная тенденция сложилась в основном за счет нефтяного сектора. Если же брать внешнюю торговлю в области сбалансированности экспортно-импортных операций потребительскими товарами, то здесь наблюдается обратная картина. В частности, значительная доля внешней торговли потребительскими товарами в республике приходится на импорт. Все это вызывает объективную необходимость совершенствования системы управления внешней торговли потребительскими товарами в Азербайджанской Республике, как в экономическом, так и организационном направлениях. В ближайшей перспективе необходимо совершенствовать экономико-организационные механизмы управления внешней торговли в Азербайджане, в том числе в сфере потребительских товаров.

Как известно, для регулирования внешнеторговой деятельности, государства используют различные методы ограничения действий конкурентов своих национальных фирм, например, препятствование их проникновению на внутренний рынок, более жесткие условия для их функционирования, запреты, повышенные экологических требований. Отсюда следует, что определение экономической эффективности управления внешней торговлей потребительскими товарами необходимо проводить в основном в трех направлениях: а) расчет экономической эффективности различных экспортных операций; б) расчет экономической эффективности импортных операций; в) расчет экономической эффективности экспортноимпортных операций совместно. Учитывая сложность данной проблемы, методика определения экономической эффективности управления внешней торговлей потребительскими товарами приведена не в теоретической части работы, а в расчетной. Ниже приводится методика определения экономической эффективности управления внешней торговлей, включая экспортноимпортные операции. Известно, что окончательная внутренняя цена экспортного товара, отражающая полные расходы экспортера на производство или закупку, транспортировку этого товара и оформление экспортной операции, может быть представлена следующей формулой:

$$
Ц_{\text {эт }}=Ц_{\text {сод }}+\mathrm{P}_{\text {тр }}+\mathrm{P}_{\text {стр }}+\mathrm{T}_{\text {п }}+\mathrm{T}_{\text {сб }}+\mathrm{P}_{\text {лок }}
$$

где Ц.эт - полная внутренняя цена экспортного товара;

$\mathrm{T}_{\text {п }}+\mathrm{T}_{\mathrm{c \sigma}}-$ соответственно таможенная пошлина и таможенные сборы;

$\mathrm{P}_{\text {тр }}+\mathrm{P}_{\text {стр},} \mathrm{P}_{\text {лок }}$ - расходы экспортера на транспортировку, страхование экспортных грузов и оформление документации, приведенные к единице экспортного товара.

Экономическая эффективность экспортной операции определяется сопоставлением полных затрат на ее осуществление, подсчитанных по формуле, с валютными поступлениями, полученными экспортером от иностранного покупателя за поставленный товар. Для обеспечения сопоставимости в методологическом плане валютные поступления в иностранной валюте переводятся в рубли (поскольку полная внутренняя цена экспортного товара рассчитывается в рублях) путем умножения на официальный курс рубля к валюте платежа [10]. 


\begin{tabular}{|c|c|c|c|c|c|c|}
\hline Impact Factor: & $\begin{array}{l}\text { ISRA (India) } \\
\text { ISI (Dubai, UAF } \\
\text { GIF (Australia) } \\
\text { JIF }\end{array}$ & $\begin{array}{l}=1.344 \\
=0.829 \\
=0.564 \\
=1.500\end{array}$ & $\begin{array}{l}\text { SIS (USA) } \\
\text { PИНЦ (Russia } \\
\text { ESJI (KZ) } \\
\text { SJIF (Morocco }\end{array}$ & $\begin{aligned} &= \mathbf{0 . 9 1 2} \\
&=\mathbf{0 . 2 0 7} \\
&=\mathbf{3 . 8 6 0} \\
&=\mathbf{2 . 0 3 1}\end{aligned}$ & $\begin{array}{l}\text { ICV (Poland) } \\
\text { PIF (India) } \\
\text { IBI (India) }\end{array}$ & $\begin{array}{l}=6.630 \\
=1.940 \\
=4.260\end{array}$ \\
\hline
\end{tabular}

C учетом изложенного, экономическая эффективность экспортной операции Ээ может быть рассчитана по формуле:

$$
\ni_{\ni}=\frac{B_{e} \cdot K_{n}}{Ц_{\ni \Pi}},
$$

где Цэп - полная внутренняя цена экспортного товара;

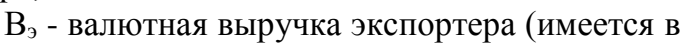
виду чистая валютная выручка с учетом возможных валютных расходов);

$K_{\text {п }}$ - официальный курс маната к валюте платежа.

В свою очередь, при расчете показателей эффективности импортных операций затраты валюты на импорт рассматриваются как полные расходы по осуществлению импортной операции и определяются по формуле:

$\mathrm{B}_{\text {п }}=\mathrm{T}_{\text {ст }} \cdot \mathrm{K}_{\mathrm{B}}+\mathrm{T}_{\text {п }}+\mathrm{T}_{\mathrm{c} \sigma}+\mathrm{A}_{\mathrm{c} \sigma}+\mathrm{HДC}+Д_{п}+\mathrm{HДC}_{\text {дп }}$

где $\mathrm{T}_{\text {ст }}$ - таможенная стоимость импортного товара;

$\mathrm{T}_{\text {п }}$ и $\mathrm{T}_{\mathrm{c} \sigma}$ - соответственно таможенные пошлины и таможенные сборы;

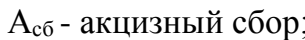

НДС - налог на добавленную стоимость со стоимости импортного товара (налогооблагаемая база - $\left.\mathrm{T}_{\mathrm{cт}}+\mathrm{T}_{\text {п }}+\mathrm{T}_{\mathrm{c \sigma}}+\mathrm{A}_{\mathrm{c} \sigma}\right)$;

Д - дополнительные расходы;

$\mathrm{HДC}_{\text {дп }}$ - налог на добавленную стоимость с дополнительных расходов.

При практических расчетах экономической эффективности импортной операции одной из самых трудно определяемых величин является $3_{\text {п }}$ (возможные национальные затраты на производство импортной продукции). Рассчитать эти затраты более трудно, если импортируемая продукция не производится в стране, например, некоторые виды современных технологий или наукоемкой продукции и т.д.

В этом случае вместо величины 3 п в расчете используется оптовая цена реализации импортированных товаров на внутреннем рынке Цоп.

Тогда показатель экономической эффективности импортной операции определяется по формуле:

$$
Э_{\text {и }}=\frac{\text { Цоп }}{\mathrm{B}_{\text {и }} \cdot \mathrm{K}_{\mathrm{B}}} \text {, }
$$

Бюджетная эффективность экспортной операции (Ээб) может быть определена по формуле:

$$
\begin{gathered}
Э_{\ni 6}=\underline{\underline{B}_{\ni}}, \underline{K_{\underline{B}}}, \\
\text { Цоп }
\end{gathered}
$$

или исчислено в абсолютном выражении

$$
Э_{э 6}=\left(B_{3} K_{в}\right)-\text { Цоп }
$$

Подобный показатель импортной операции найдем по формуле

$$
Э_{\text {иб }}=\frac{\text { Цоп }}{\mathrm{B}_{\text {и }} \cdot \overline{\mathrm{K}}_{\mathrm{B}}},
$$

или исчислен в абсолютном выражении

$$
Э_{э 6}=\text { Цоп - }\left(\mathrm{B}_{\text {и }} \cdot \mathrm{K}_{\mathrm{B}}\right)
$$

где $\mathrm{B}_{\ni} \mathrm{K}_{2}$ - чистые валютные поступления, переведенные в национальную валюту;

$\mathrm{B}_{\text {и }} \mathrm{K}_{\mathrm{B}}$ - полные валютные затраты на финансирование импортной операции, выраженные в национальной валюте.

На величину эффективности экспорта и импорта в значительной степени влияют уровень внешнеторговых (контрактных) цен, изменение структуры торговли, а также затраты труда на производство товаров (полные внутренние цены экспортных товаров), возможные национальные затраты на производство импортируемой продукции или ее аналогов (цена реализации импортированных товаров на внутреннем рынке). На показатели эффективности экспорта и импорта влияет также изменение официального курса национальной валюты - маната к валюте платежа.

Отметим что, в практике имеется ряд факторов, которое оказывает серьезные влияния на внешнеторговый оборот страны. В Таблице 1 дано влияние отдельных факторов на внешнеторговый оборот Азербайджанской Республике по оценкам 2015 года. 


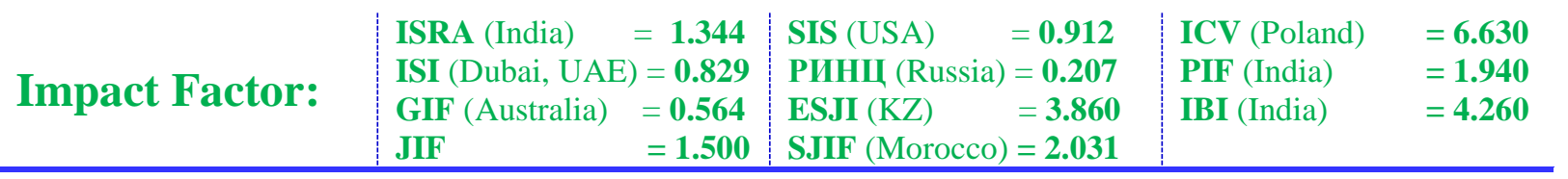

Таблица 1

Влияние отдельных факторов на внешнеторговый оборот Азербайджанской Республики (по показателю средних структурных сдвигов)

\begin{tabular}{|c|c|c|c|c|c|c|c|c|}
\hline & 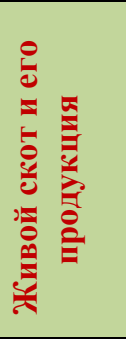 & 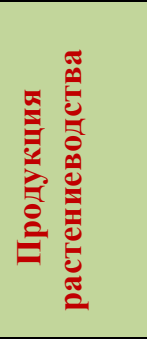 & 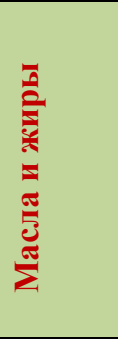 & 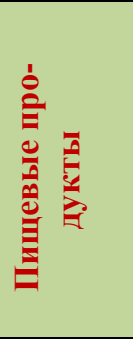 & 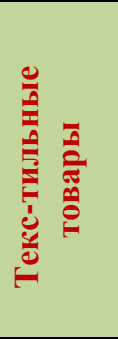 & 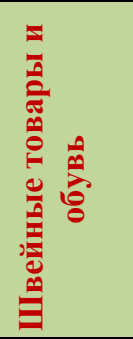 & 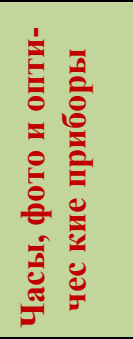 & 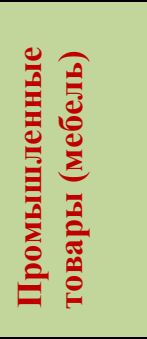 \\
\hline 1 & 2 & 3 & 4 & 5 & 6 & 7 & 8 & 9 \\
\hline \multicolumn{9}{|c|}{2003 год } \\
\hline $\begin{array}{l}\text { Внешнеторг } \\
\text { овый оборот }\end{array}$ & $-37,26$ & $-165,2$ & 2,6 & $-382,7$ & $-8,8$ & $-2,05$ & $-36,24$ & $-54,38$ \\
\hline Экспорт & 0,14 & 59,0 & 25,4 & 24,7 & 12,8 & 0,00 & 0,16 & 0,12 \\
\hline Импорт & 37,4 & 223,2 & 22,8 & 407,4 & 21,6 & 2,05 & 36,4 & 54,5 \\
\hline \multicolumn{9}{|c|}{2005 год } \\
\hline $\begin{array}{c}\text { Внешнеторг } \\
\text { овый оборот }\end{array}$ & $-26,64$ & $-8,2$ & 5,7 & $-464,6$ & $-5,4$ & $-1,55$ & $-3,07$ & $-128,19$ \\
\hline Экспорт & 0,06 & 146,8 & 25,5 & 48,2 & 10,5 & 0,00 & 0,16 & 0,21 \\
\hline Импорт & 26,7 & 155,0 & 19,8 & 612,8 & 15,9 & 1,55 & 3,23 & 128,4 \\
\hline \multicolumn{9}{|c|}{2007 год } \\
\hline $\begin{array}{l}\text { Внешнеторг } \\
\text { овый оборот }\end{array}$ & $-17,48$ & $-224,0$ & 8,2 & $-832,1$ & $-4,9$ & $-1,0$ & $-72,06$ & $-20,4$ \\
\hline Экспорт & 0,12 & 98,9 & 27,9 & 127,9 & 7,0 & 0,00 & 0,84 & 0,5 \\
\hline Импорт & 17,6 & 322,9 & 19,7 & 960,0 & 11,9 & 1,0 & 72,9 & 20,9 \\
\hline \multicolumn{9}{|c|}{2010 год } \\
\hline $\begin{array}{l}\text { Внешнеторг } \\
\text { овый оборот }\end{array}$ & $-17,81$ & $-247,3$ & $-7,3$ & $-894,3$ & $-8,2$ & $-2,17$ & $-97,6$ & $-23,1$ \\
\hline Экспорт & 0,46 & 104,6 & 34,5 & 140,6 & 9,9 & 0,00 & 1,35 & 0,72 \\
\hline Импорт & 18,27 & 351,9 & 41,8 & 1034,9 & 18,1 & 2,17 & 99,0 & 23,8 \\
\hline \multicolumn{9}{|c|}{ Оценка 2015} \\
\hline $\begin{array}{l}\text { Внешнеторг } \\
\text { овый оборот }\end{array}$ & $-16,8$ & $-231,1$ & $-8,4$ & $-902,3$ & $-8,9$ & $-2,23$ & $-101,1$ & $-267,7$ \\
\hline Экспорт & 0,49 & 103,9 & 35,8 & 148,3 & 10,3 & 0,00 & 1,38 & 0,85 \\
\hline Импорт & 19,1 & 362,3 & 43,2 & 1081,4 & 19,5 & 2,21 & 97,1 & 27,2 \\
\hline
\end{tabular}

Примечание: Таблица составлено автором по материалам Государственного Статистического Комитета Азербайджанской Республики. http://www:stat.gov.az.

Как видно, почти по всем товарным группам внешнеторгового оборота получены отрицательные показатели. По отдельным позициям имеются определенные сдвиги, но они настолько мизерные, что говорить об улучшении ситуации во внешней торговле потребительскими товарами не приходится. Указанные факторы обусловливают особенности рыночного механизма внешней торговли, побуждают их участников вносить коррективы в принципы и методы своей рыночной политики. С одной стороны, возникающие возможности выхода на внешний рынок ставят перед фирмой задачу приспособления всего комплекса маркетинга к особенностям и условиям экономической среды в стране-партнере [11]. В то же время необходимы простые и стандартные приемы и решения, обеспечивающие четкое и контролируемое

ISPC Innovations in science,

выполнение принятых вариантов. С другой стороны, у продавца, и тем более производителя, возникает задача поиска и внедрения наилучшей организационной формы своей внешнеэкономической деятельности, учитывающей наряду с условиями и факторами, свойственными внутреннему рынку, и отмеченные выше особенности внешней торговли [12; 13]. Кроме того, не может не учитываться фактор риска, связанный со степенью экономической и политической нестабильности в стране-партнере. Значение рискового фактора тем более возрастает при таких формах внешней торговли, как создание и деятельность иностранных и совместных предприятий, инвестиционные проекты, производственная и научно-техническая специализация и кооперирование и т.д. 
По итогам исследований современных экономико-организационных аспектов управления внешней торговлей потребительскими товарами в современных условиях, можно сделать следующие выводы:

- глубокий анализ ресурсного обеспечения перестройки структуры управления внешней торговли потребительскими товарами показал, что в Азербайджанской Республике необходимо реформирование всей структуры промышленного производства путем развития обрабатывающей промышленности, так как именно данная сфера является отправной точкой производства потребительских товаров для внешнего рынка;

- исследование состояния системы управления внешней торговлей потребительскими товарами и ее структурный анализ показал, что в этой сфере имеются достаточно сложные проблемы, к числу которых можно отнести такие вопросы, как реорганизация системы отраслевого управления внешней торговли; более тесная координация внешней и внутренней торговли страны; изменения системы управления внешней торговли с учетом развития информационных технологий и других коммуникаций с целью устранения барьеров входа и выхода на внешний рынок;

- одновременно реформирование системы управления внешней торговли должна быть построена с учетом стратегий современных фирм, к числу которых следует отнести: стратегию диверсификация; стратегию интернационализации; стратегию кооперации; технологические стратегии; общие стратегии управления;

- для оптимального прогнозирования оценка и распределения потребительских товаров на внешнем рынке предлагается разработка стратегии покрытия рынка, определение длины и контроля над каналом распределения, расчет взвешенной оценки конкурентной силы, прогнозная оценка конкурентоспособности потребительских товаров, расчет конкурентной цены товара, оценка сравнительной полезности конкурентного положения сегмента потребительских товаров на внешнем рынке, разработка потенциала маркетингового инструментария;

- и наконец, в целом для повышения экономической эффективности экспортноимпортных операций потребительскими товарами в республике в работе предлагается комплексный и системный подход с учетом средних структурных сдвиг экспорта и импорта, ассортиментные сдвиги, географическую структуру и т.д.

\section{References:}

1. Aliyev R.F. (2008) Osnovnyye problemy v protsesse vstupleniya Azerbaydzhanskoy Respubliki vo vsemirnuyu torgovuyu organizatsiyu. Avtoreferat dis. AGEU. Baku.: 2008, - 25 p.

2. Gafarov T.K. (2004) Problemy regulirovaniya vneshneekonomicheskikh svyazey Azerbaydzhana $\mathrm{v}$ usloviyakh perekhodnoy ekonomiki. Avtoreferat dis. AGEU. Baku.: 2004. - 26 p.

3. Lomakin V.K. (2004) Mirovaya ekonomika. M.:YUNITI. 2004, - 412 p.

4. Prokushev Ye.F.

Vneshneekonomicheskaya

M.:Dashkov i K. 2009, - 500 p.

deyatel'nost'.

5. (2008) Ekonomika torgovogo predpriyatiya: torgovoye delo. Pod red. L.A.Bragina. M.:INFRA-M.2008, p. 52-55, 70-91.

6. (2009) Ekonomicheskaya strategiya firmy. Pod red. A.P.Gradova. SPb.: Spets-Lit. 2009, - 586 p.

7. Petrov K.N. (2010) Upravleniye otdelom prodazh. M.Vil'yams. 2010, - 336 p.
8. Puzakova Ye.P. (2004) Mirovaya ekonomika i mezhdunarodnyye ekonomicheskiye otnosheniya. M.:Feniks. 2004, p.210-211.

9. (2007) Upravleniye vneshnimi rynochnymi protsessami: problemy i perspektivy razvitiya. Pod obshch. Red. prof. A.G.Samedova. Moskva-Baku.: Mars-Print. 2007, p. 105-106.

10. Sel'tsovskiy V.P. (2004) Ekonomikostatisticheskiye metody analiza vneshney torgovli. M.:Finansy i statistika. 2004, -p.319.

11. Samedov A.G., Safarova V.T. (2002) Upravleniye kommercheskoy deyatel'nost'yu torgovykh firm. Baku.: Mars-Print. 2002, p.120.

12. (2008) Upravleniye sub"yektami rynka (teoriya i praktika). Pod obshch. red. prof. A.G.Samedova. Moskva-Baku.: Mars-Print. 2008, $-684 \mathrm{p}$.

13. (2006) Effektivnost' upravleniya rynochnymi protse ssami. Pod obshch. red. prof. A.G.Samedova, Moskva-Baku.: Mars-Print. 2006, - 562 p. 